\title{
Gestão ambiental e democracia: análise crítica, cenários e desafios
}

\author{
Environmental management: critical analysis, scenarios and challenges
}

Marcelo Firpo de Souza Porto ${ }^{1}$

Gabriel Eduardo Schütz ${ }^{2}$

${ }^{1}$ Centro de Estudos da Saúde do trabalhador e Ecologia Humana, Escola Nacional de Saúde Pública Sergio Arouca, Fundação Oswaldo Cruz. Av. Leopoldo Bulhões 1480, Manguinhos. 21041210 Rio de Janeiro RJ. marcelo.firpo@ensp.fiocruz.br ${ }^{2}$ Instituto de Estudos em Saúde Coletiva, Universidade Federal do Rio de Janeiro.

\begin{abstract}
This article discusses the limits, alternatives and challenges of environmental management in contemporary globalized capitalist societies. It is based on a critical analysis supported by authors from social sciences, political ecology and public health. To this end, we systematize the meaning of hegemonic environmental management in terms of eco-efficiency and its limits to tackle environmental risks and construct democratic processes and societies. We developed four ideal scenarios involving possible combinations of environmental management and democracy. This model served as a base, together with academic studies and the theoretical and militant experience of the authors, for a reflection on the current characteristics and future trends of environmental management and democracy, with emphasis on the reality of Latin America, specifically Brazil. Lastly, we discuss possibilities for social transformation taking into consideration the contradictions and emancipatory alternatives resulting from confrontations between hegemonic tendencies of the market and counter-hegemonic utopias and social movements. The latter assume principles of environmental justice, economic solidarity, agro-ecology and sustainability as well as the construction of new epistemologies.
\end{abstract}

Key words Environmental management, Democracy, Future scenarios, Eco-efficiency, Citizen control
Resumo $O$ artigo discute limites, alternativas $e$ desafios da gestão ambiental nas sociedades contemporâneas inseridas no capitalismo globalizado a partir de uma análise crítica apoiada em autores das ciências sociais, da ecologia politica e da saúde coletiva. Para isso, sistematizamos o significado da gestão ambiental hegemônica em sua vertente da ecoeficiência e seus limites para o enfrentamento dos riscos ambientais_e para a construção de processos e sociedades mais democráticos. Construimos quatro tipos ideais de cenários envolvendo possiveis combinações entre gestão ambiental e democracia. Este modelo serviu de base, juntamente com trabalhos acadêmicos e a experiência teórica e militante dos autores, para uma reflexão sobre as características atuais e as tendências futuras de gestão ambiental e democracia, com ênfase na realidade latino-americana, mais especificamente na brasileira. Por fim, discutimos possibilidades de transformação social a partir das contradições e alternativas emancipatórias decorrentes das confrontações entre tendências hegemônicas do mercado e contra-hegemônicas provenientes de utopias e movimentos sociais, estas assumindo princípios da justiça ambiental, da economia solidária, da agroecologia e da sustentabilidade, bem como da construção de novas epistemologias.

Palavras-chave Gestão ambiental, Democracia, Cenários futuros, Ecoeficiência, Controle cidadão 


\section{Introdução}

Este artigo busca discutir as possibilidades de gestão ambiental nas sociedades contemporâneas inseridas no capitalismo globalizado a partir de uma análise crítica apoiada em alguns autores das ciências sociais, da ecologia política e da saúde coletiva. A importância desta reflexão parte de dois pressupostos ${ }^{1,2}$ : (a) a agudização dos problemas ambientais na atualidade, que passa a ser caracterizada como crise a partir do consumo sem precedentes dos recursos naturais, da degradação dos ecossistemas, da dramática redução da biodiversidade e do agravamento dos riscos ambientais, em particular os riscos ecológicos globais tais como a destruição da camada de ozônio, a poluição química transfronteiriça e as mudanças climáticas globais decorrentes dos gases de efeito estufa; (b) o uso amplamente disseminado pela sociedade e pela academia da categoria gestão ambiental como principal estratégia de resolução dos problemas ambientais, associado a uma concepção de ecoeficiência que enfatiza ferramentas como tecnologias limpas e, mais recentemente, a economia verde. Tal uso, entretanto, frequentemente oculta o contexto histórico e social dos problemas ambientais despolitizando o debate sobre os sentidos do desenvolvimento e da sustentabilidade.

O artigo está organizado da seguinte forma: inicialmente resgatamos a etimologia do termo ecologia para discutir sua fragmentação, bem como as contradições e os limites da democracia liberal hegemônica orientada pelos interesses de mercado para lidar com a sustentabilidade ambiental e a justiça social. Em seguida, analisamos o conceito de gestão ambiental e seus quatro pilares no escopo da ecoeficência autorregulada, quais sejam: (i) sistema de gestão ambiental; (ii) certificação ambiental; (iii) processos de produção mais limpa; e (iv) avaliação do ciclo de vida. A ecoeficiência, visão de cunho gerencial e econômico que orienta de forma hegemônica o conceito de gestão ambiental, pode ser entendida como a principal resposta de setores empresariais e organismos internacionais à crise ambiental discutida pela ONU nas últimas décadas, tendo seu apogeu na Rio 92.

Logo após, buscamos desenvolver uma contribuição teórica original em duas etapas: inicialmente construímos um modelo de tipos ideais de gestão ambiental a partir da combinação da intensidade de dois elementos considerados chaves para a sustentabilidade e a justiça social. De um lado, a gestão ambiental avaliada a partir da incorporação ou não dos quatro pilares propostos para sua eficiência; e de outro a democracia, analisada não em seu sentido descritivo, como forma de governo e modo de vida de uma sociedade de mercado, mas em seu sentido substancial e normativo ${ }^{3}$, como forma de sociedade interessada em garantir, para todos os seus membros, a liberdade necessária à concretização e ao desenvolvimento de suas capacidades, incluindo os direitos humanos fundamentais e a distribuição equitativa de poder entre todos os cidadãos.

O modelo elaborado gerou quatro tipos ideais entre o pior (menos gestão e menos democracia) e o melhor (mais gestão e mais democracia), os quais foram utilizados tanto para refletir sobre os limites e as possibilidades da gestão ambiental no contexto atual como para cenários futuros, assumindo de forma simplificada alguns pressupostos metodológicos do planejamento estratégico e da construção de cenários futuros ${ }^{4}$. Para a análise foram levados em consideração cinco parâmetros principais: econômico (externalidades), técnico (avanço técnico-científico), epistemológico (incertezas), político (controle cidadão) e comunicativo (soberania informativa), os quais serão explicados mais a frente. A base empírica para a análise considera as características dos problemas ambientais, em especial no caso brasileiro e dos demais países latino-americanos, tendo por referência trabalhos que os analisam criticamente no interior das sociedades contemporâneas ${ }^{1,5-7}$, assim como a experiência teórica, prática e militante dos autores no campo da saúde ambiental e mobilizações por justiça ambiental ${ }^{2,8}$.

\section{Ambiente, gestão e democracia: uma visão crítica}

O termo Ökologie (Ecologia) provém do antigo vocábulo grego oikos que significa casa, lugar onde se habita. A ação de fazer habitável a casa expressava-se oikopoióse e oikonomos, a gestão da casa. O oikos na cultura clássica denominava a unidade básica de produção e satisfação das necessidades vitais, e o oikonomos (economia) referiase às normas de administração dos bens ou rendimentos domésticos. Nas sociedades modernas, fazer gestão define-se como a ação de dirigir, regular, governar, administrar. Por gestão ambiental entende-se, portanto, a ação de gerir o ambiente, seja em entornos localizados (trabalho/fábrica/casa), ampliados (bairros, cidades, regiões) ou globais, envolvendo, por exemplo, diferentes países, continentes, oceanos ou o planeta como 
um todo. Sendo o ambiente um bem comum, sua gestão incumbe à esfera social, na qual processos vitais dos indivíduos adquirem relevância pública. Quando a Polis começou a gerir a esfera social, a economia doméstica (oikonomos) se transformou em economia política ${ }^{9}$. No entanto, o debate sobre como devem ser geridos os aspectos ambientais do oikos é mais recente, demandando uma integração a priori da Ökologie com oikopóios e oikonomos, o que vem ocorrendo nas últimas décadas nas ciências sociais e da vida, por exemplo através do desenvolvimento da Ecologia Política e da Economia Ecológica ${ }^{2,5}$.

A Ecologia explica que os organismos dispõem da capacidade para gerir seu habitat como estratégia de sobrevivência; porém, não consegue explicar sem reducionismos a intervenção na natureza mediada pela ação humana, a qual resulta de processos históricos e envolve uma complexidade emergente ou reflexiva, característica dos sistemas sociais, técnicos ou mistos os quais não podem ser explicados de forma mecanicista ou funcionalista ${ }^{1,6}$. Um aspecto importante que diferencia os humanos dos demais seres vivos é o fato de gerar relações entre congêneres que condicionam seu comportamento posterior: em cada momento histórico as combinações de propriedade / acesso / uso dos recursos disponíveis estão determinadas pelas relações sociais de produção, as quais, por sua vez, condicionam em grande parte as formas diferenciadas de relacionamento das sociedades com a natureza ${ }^{6}$. Este relacionamento produz o "ambiente", uma construção determinada pela conjunção histórica das forças sociais que conseguem impor a sua hegemonia.

Atualmente, observam-se hegemonias bem consolidadas $^{5,7-9}$ : (i) A democracia liberal capitalista como sistema em que prevalece a lógica econômica, e a política se torna um problema apenas administrativo; (ii) as leis de mercado como instrumento de regulação das relações sociais; (iii) a governança como instrumento de mitigação dos conflitos sociais; (iv) a prioridade lexical da propriedade e do individualismo como valores morais; (v) uma ciência "normal" baseada na objetividade e na neutralidade que sistematicamente desconsidera a complexidade, contextos, valores e incertezas, e dessa forma se integra mais facilmente às demandas regulatórias do mercado. Diante delas, distintos dispositivos de natureza psicológica e simbólica produzem subjetividades de cunho político que ocultam ou manipulam as ações históricas que se encontram por detrás de temas e problemas debatidos publicamente. Mutatis mutandis isso pode ser observa- do na própria ideia de gestão ambiental, tanto no senso comum quanto no campo acadêmico ${ }^{7}$. Invisibilizados seus determinantes históricos, ela passa a ser concebida não como uma ação política que busca dar sustentabilidade ao capitalismo e a interesses do "mercado" (oikonomos), mas como uma maneira neutra de administrar os ecossistemas que dão suporte à vida (oikopóios) e controlar riscos. De certa forma podemos atribuir à gestão ambiental um caráter de fetiche: assim como o fetichismo da mercadoria vem tornando invisível o trabalho humano, o fetichismo da subjetividade faz com que as pessoas acreditem firmemente na autonomia de seu poder de escolha, muito embora seus desejos possam estar determinados em forma heterônoma pelos dispositivos simbólicos do mercado ${ }^{7,10}$.

Nesta perspectiva, a gestão ambiental hegemônica insere-se na crítica que Nunes ${ }^{11}$ faz ao modelo da "dupla delegação" presente nas democracias modernas: de um lado, colocando de forma exclusiva a competência na produção de conhecimento nas mãos de especialistas e cientistas, e de outro a político-administrativa nas mãos de políticos eleitos, funcionários do Estado e suas instituições. O cidadão é reduzido ao papel de mero eleitor, consumidor e "usuário" de serviços e "opções" políticas de cuja formulação não participa, ampliando-se a lógica instrumental de mercado para o conjunto da vida social. Neste contexto, a sujeição das relações sociais à ordem hegemônica precisa invisibilizar fraquezas e contradições do sistema, em especial a não universalidade da participação, os conflitos socioambientais e as demandas de saúde colocadas sob a ótica dos direitos e da justiça ambiental, bem como formas de conhecimento, solidariedade e sustentabilidade incompatíveis com interesses dominantes. Portanto, podemos entender a concepção hegemônica de gestão ambiental como uma ferramenta de governança, ou seja, uma forma de administrar a conflitividade social decorrente das contradições e fragilidades próprias do modelo de acumulação capitalista ${ }^{7}$.

Uma das fragilidades da gestão ambiental e sua prática de governança envolve a questão democrática da participação cidadã. Porém, a participação negligenciada não significa ausência de participação, como mostra um estudo europeu ${ }^{12}$ que identificou seis formas de governança: (1) discricionária: Estado sem a participação civil; (2) educacional: mídia e enquetes de opinião pública; (3) deliberativa: direcionada à busca de consensos, tendo a participação pública o objetivo de dar suporte às escolhas técnicas dos especia- 
listas; (4) corporativas: as soluções dos conflitos de interesses são estabelecidas em processos fechados de negociação e deliberação; (5) de mercado: a participação é concebida como fonte de competitividade, e o público como consumidor; e, finalmente, (6) agonística: se realiza em condições de confrontação incluindo ações diretas (manifestações, boicotes); tende a ser ocultada ou considerada ilegítima, sendo frequentemente punida através da criminalização dos ativistas e seus parceiros. Contudo, algumas demandas podem acabar sendo reconhecidas em processos de negociação posteriores às ações diretas.

Autores da vertente ecomarxista ${ }^{8}$ apontam as fragilidade do modelo hegemônico associadas às duas contradições fundamentais do próprio capitalismo. A primeira, central no período inicial do capitalismo industrial até a o início da segunda metade do século XX, relaciona-se com as condições de trabalho, tendo como principais protagonistas os trabalhadores expropriados da sua produção (alienação, mais-valia). Já a segunda, crescentemente importante desde então, está associada às condições de produção, o que incluiria as problemáticas ambientais, de gênero, étnicas dentre outras. Seus principais protagonistas são coletivos contra-hegemônicos organizados em torno de suas próprias agendas de mudança social, como feministas, ambientalistas, povos tradicionais, agricultores familiares ligados à agroecologia, organizações de justiça ambiental, dentre outros ${ }^{13,14}$.

$\mathrm{Na}$ perspectiva hegemônica, a gestão ambiental restringe o espaço de solução de conflitos às instâncias institucionais consolidadas e à busca de consensos por mecanismos como composição, negociação ou decisão por maioria. Tais mecanismos, contudo, assumem que as demandas sociais consideradas legítimas são apenas aquelas cujas soluções não implicam transformações radicais ou estruturais da ordem social instituída. Portanto, há um processo social de ocultar dissensos e isolar as reclamações, sejam elas parcialmente satisfeitas ou não, para que os atores sociais demandantes constituam identidades sociais fragmentadas, seja na condição de vulneráveis que necessitam ações de ajuda, seja na condição de ilegítimos ou inimigos. Em contrapartida, existe uma pluralidade de demandas, mobilizações e realizações por direitos coletivos que, através de sua articulação equivalencial, produzem subjetividades, plataformas e agendas mais amplas dos atores, redes e movimentos sociais, sendo fundamentais para a transformação social $^{15}$.
No modelo da dupla delegação ${ }^{11}$, um grupo selecionado de atores sociais (stakeholders) e peritos "credenciados" - cuja base é a da ciência normal pretensamente neutra e objetiva - participam de discussões de natureza dita técnica na perspectiva dos interesses econômicos dominantes. A atual noção de gestão ambiental encontra a sua origem nesta estratégia apolítica, que dificulta as articulações equivalenciais necessárias para produzir ações coletivas transformadoras por parte de atores e movimentos sociais que se posicionam enquanto portadores de direitos (stakerights).

\section{Ecoeficiência e tipos ideais de gestão ambiental}

Atualmente, a política ambiental das grandes corporações e, em parte, das organizações do Estado é estruturada pela formulação de diretrizes de Ecoeficiência que compõem sistemas de gestão autorregulados. A Ecoeficiência é uma política estratégica que incorpora a responsabilidade corporativa; encoraja as empresas a se tornarem mais inovadoras e competitivas; propaga a ideia de autorregulação - em contraposição à ação regulatória e fiscalizadora do Estado - e amplia a adesão voluntária ${ }^{14}$. Trata-se de uma resposta conceitual e política desenvolvida por grandes corporações e associações industriais e empresariais para responder a vários desafios apresentados na Rio92 sob a lógica da gestão eficiente.

Para fins analíticos, propõe-se aqui caracterizar tipos ideais dos atuais modelos de gestão ambiental. Entende-se que os tipos ideais não são descrições exatas da realidade, mas intentos de construir, a partir de elementos essenciais, uma tipologia que faça inteligível a caótica e dispersa evidência acumulada na experiência e que contribua na análise de tendências atuais e futuras ${ }^{4}$. Os elementos essenciais tipificadores aqui considerados são os quatro instrumentos que definem a Ecoeficiência de um empreendimento, isto é, a prática parcial ou total de quatro ferramentas interrelacionadas: (i) Sistema de gestão ambiental (SGA); (ii) Certificação ambiental; (iii) Processos de produção mais limpa $(\mathrm{P}+\mathrm{L})$; e, (iv) Avaliação do ciclo de vida $(\mathrm{ACV})^{15}$. A implantação de um SGA permite à empresa reduzir custos de produção racionalizando insumos materiais e energéticos, muitas vezes limitado aos processos administrativos e de publicidade. O sistema de certificação ambiental mais geral disponível, e aplicável a todos os processos produtivos é a sé- 
rie de normas ISO 14000, formulado pela organização não-governamental International Standardization Organization (ISO) e que trata de temas como a implantação do SGA, a realização de auditorias ambientais, a avaliação de desempenho ambiental, as rotulagens e as declarações ambientais dos produtos e a própria $\mathrm{ACV}$. A ACV é um procedimento que permite ponderar os impactos ambientais de um produto em forma integrada, desde seu design até a disposição final dos resíduos. Adotar procedimentos de $\mathrm{P}+\mathrm{L}$ significa escolher os procedimentos menos poluidores disponíveis em cada etapa do processo de produção, por exemplo, averiguando se determinada fábrica, processo produtivo ou produto adota a Best Available Technology (BAT).

Para fins desta tipificação, considerar-se-á que os compromissos de cada item são postos em prática (independente do alcance dos seus resultados), estabelecendo quatro tipos ideais de gestão ambiental: (1) não incorpora nenhum instrumento de autorregulação; (2) instrumenta apenas a certificação do SGA; (3) instrumenta tanto a certificação do SGA quanto a P+L; e, (4) instrumenta as quatro ferramentas. Uma vez que a lógica que determina a Ecoeficiência autorregulada é a economia de mercado, resulta interessante começar a análise destes tipos ideais por meio de um parâmetro econômico: as externalidades, quer dizer, efeitos (positivos ou negativos) que recaem sobre terceiros não implicados na sua produção. As externalidades ambientais negativas expressam impactos sociais à saúde $\mathrm{e}$ ao ambiente que não são incorporados na formação dos preços. As externalidades, junto com os free-riders, são considerados fatores de distorção do mercado livre. Os free-riders são indivíduos ou coletivos que participam do benefício de uma atividade sem contribuir nem para o custo da mesma, nem para os custos das externalidades negativas ${ }^{14}$.

Do ponto de vista das externalidades, o Tipo 1 aparece como o típico modelo de gestão laissez faire: os custos socioambientais externalizados não são suportados por aqueles que colhem os benefícios. Exemplos são os pequenos empreendimentos rudimentares, atividades econômicas informais e empresas terceirizadas que realizam o "trabalho sujo" de grandes corporações privadas ou estatais. Cabe destacar que as certificações ambientais são outorgadas a linhas de produção determinadas, e não às pessoas físicas ou jurídicas que as desenvolvem, o que contribui para encobrir a presença de empresas do tipo 1 dentro de cadeias produtivas com empresas cer- tificadas, o que significa a coexistência camuflada do tipo 1 junto aos tipos 2 ou mesmo 3 .

No Tipo 2 há uma busca por reduzir progressivamente o impacto ambiental do processo produtivo, racionalizando o máximo possível o consumo de recursos materiais (água, matérias primas, descartáveis) e energéticos (eletricidade, combustíveis). Desta forma há uma incorporação de externalidades, porém difusas e nem sempre territorializadas junto à empresa. À diferença do Tipo 3, o Tipo 2 não assume necessariamente o compromisso de utilizar a tecnologia mais limpa disponível, não incorporando diversas externalidades associadas aos riscos, com empresas que exibem como única certificação ambiental a ISO 14001.

Embora o Tipo 3, ao se comprometer com a $\mathrm{P}+\mathrm{L}$ incorpore mais externalidades que o Tipo 2, ainda o faz somente com respeito aos processos produtivos diretamente envolvidos. Ou seja, continua sem assumir as externalidades derivadas da utilização e disposição final dos produtos resíduos - desses processos. Por exemplo, uma indústria química pode exibir as melhores certificações ambientais disponíveis para garantir que produz um agrotóxico com segurança e com a melhor tecnologia disponível (BAT) sem, no entanto, discutir os impactos que a utilização e destino final dos seus produtos e outros resíduos possam vir a provocar no tecido social, no ecossistema e na saúde dos trabalhadores rurais.

Por último, o Tipo 4, ao instrumentar a ACV do produto, incorporaria, em tese, o conjunto das externalidades devidas a riscos conhecidos. Entretanto, o tipo 4 também pode gerar efeitos perversos camuflando tipos inferiores associados às cadeias produtivas e ao comércio internacional, através de um metabolismo social insustentável e injusto ${ }^{14}$. Pode-se dizer, ainda, que as diretrizes corporativas comumente são formuladas de forma demasiado genérica, permitindo omissões importantes. Ao mesmo tempo, é possível identificar diversos casos em que a ecoeficiência autorregulada produziu inovações tecnológicas e organizacionais favoráveis ao ambiente, ao melhor controle de riscos e à prevenção de acidentes ${ }^{10}$.

Todavia, a problemática das externalidades adquire outra dimensão argumentativa quando se introduz na discussão o parâmetro incertezas. Do ponto de vista epistemológico, é difícil afirmar que os riscos serão sempre reconhecidos baseados em evidências científicas em situações de alta complexidade que marcam o campo ambiental, os riscos industriais e os efeitos à saúde. As 
incertezas representam um dilema para a governança hegemônica, pois aceitá-las significaria reconhecer que as decisões em matéria ambiental devem fundamentar-se em critérios políticos e ético-valorativos, e não apenas discussões técnicas, daí sua manipulação na defesa de interesses econômicos envolvendo indústrias e produtos perigosos como o fumo ${ }^{16}$. Uma vez introduzidas as incertezas, o modelo autorregulado hegemônico é confrontado pelo Princípio da Precaução ${ }^{17}$, que além de ter vocação universal, teria regência mesmo sem o rigor das certezas científicas.

Há, ainda, outros dois testes pelos quais a ecoeficiência autorregulada não consegue passar satisfatoriamente: o do controle cidadão e o da soberania informativa. O controle cidadão significa a capacidade de ação fiscalizadora da sociedade civil organizada, e existem limites mesmo tendo sido normalizado em várias legislações nacionais em relação às atividades de governos e de instituições públicas, inclusive porque os processos de certificação e auditoria envolvem entes privados que, sob a lógica de mercado, assumem formas restritivas de participação, não de cidadãos, mas de consumidores.

Diversas corporações têm divulgado ao público relatórios de desempenho social e ambiental, sugerindo grandes esforços feitos em inovações tecnológicas e investimentos ambientais, mas omitindo causas e contextos ${ }^{17,18}$. O fato das grandes empresas privadas usarem a comunicação como uma peça crucial da governança hegemônica e marketing dificulta o exercício democrático da soberania informativa, entendida como o livre e efetivo acesso à informação, valorizada como um bem público e não como uma mera mercadoria, já que o direito a estar adequadamente informado é crucial à cidadania, pois alicerça a autonomia dos sujeitos.

Sem acesso ao conhecimento sobre os procedimentos envolvidos na obtenção de uma certificação ambiental, a sociedade tende a relacionála a uma espécie de premiação por não poluir ${ }^{19}$, sem identificar os determinantes históricos inseridos na governança hegemônica. Por isso, a consolidação da soberania informativa é tão importante, não apenas para desconstruir o fetiche da gestão, mas para a consolidação de uma democracia mais justa e inclusiva.

Apesar das críticas, é importante ressaltar que as ferramentas de gestão ambiental não podem ser desprezadas em função de sua origem na lógica de mercado: elas têm imbuído trabalho histórico e fazem parte das conquistas tecnológicas e materiais da humanidade, que poderemos usu- fruí-las no futuro desde que isso não implique a geração de privilégios injustos. Portanto, um desafio central consiste em como reformular e democratizar os instrumentos de gestão ambiental assumindo o seu caráter político.

\section{Gestão e democracia: presente e futuro em quatro cenários}

A partir dos tipos ideais de gestão desenvolvidos, propomos aqui um exercício teórico de construir quatro cenários que, de forma sintética, esquematizam possíveis ordens sociais decorrentes das diferentes combinações da gestão ambiental com a democratização da sociedade. Para isso, nos apoiamos nos estudos de cenários utilizados como referencial de futuros possíveis e alternativos, permitindo a reflexão sobre a realidade em que se vive e diante da qual se planeja construir alternativas, incluindo os sonhos e utopias por um mundo melhor ${ }^{4}$.

A Figura 1 mostra o esquema que define os cenários: acima e à direita os parâmetros aumentam, ao passo que abaixo e à esquerda se reduzem. Metaforicamente, o cenário 1 (menos democracia, menos gestão) é a combinação mais perversa da economia laissez faire com ausência de contrato social. A violência não é monopólio do Estado, as relações de trabalho são indignas e a exploração dos recursos naturais é predatória. Não há políticas públicas que atenuem as consequências socioambientais e sanitárias da destruição dos ecossistemas, com exclusão social e ex-

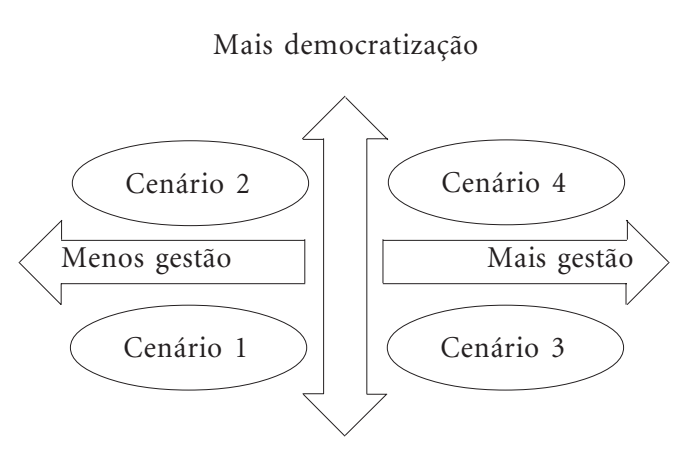

Menos democratização

Figura 1. Os quatro diferentes cenários socioambientais construídos a partir da ponderação combinatória de gestão ambiental com democracia. 
pulsão territorial, sendo as culturas tradicionais os coletivos mais vulneráveis. Impera a ganância, a injustiça na distribuição da riqueza e não há garantias para o exercício dos direitos fundamentais e para o acesso à informação. Os principais beneficiários deste modelo são os apropriadores de recursos naturais e da força de trabalho (geralmente extraterritoriais) e os free-riders (frequentemente violentos e corruptos), gerando-se um enorme déficit democrático e a intensificação de assimetrias de poder. A vulnerabilidade institucional se apresenta através da ausência de políticas públicas ou seu forte atrelamento aos interesses privados ou, ainda, da criminalização de coletivos sociais. A ausência do Estado também facilita o controle monopólico da produção simbólica da informação na mídia, a corrupção generalizada e a proliferação de práticas violentas e mafiosas de repressão. Este cenário é mais factível em territórios mais afastados dos centros onde se tomam as decisões que dão governança à economia capitalista, mesmo dentro de países onde cenários mais vantajosos encontram-se presentes.

O cenário 2 (menos democracia, mais gestão) parece ser o mais comum nos territórios que participam da economia capitalista globalizada sem ter consolidado práticas de participação cidadã mais efetivas. Neste cenário, a exploração dos recursos naturais e da força de trabalho obedece à lógica do mercado. Em geral, o poder público acompanha os interesses do poder econômico sem anular ou excluir a existência de instituições públicas, convivendo com elas em regime de controle e manipulação, inclusive em processos pro forma de licenciamento ambiental ou de certificações para atender exigências do mercado. A gestão ambiental é implantada apenas como um instrumento para esses fins, podendo incluir práticas seguras e tecnologias limpas desde que sua adoção seja economicamente interessante frente a diversas externalidades negativas que ainda permanecem. A exploração encontra limites nas pressões da sociedade civil organizada em situações de conflito frequentemente invisibilizadas, o que é revertido através de mobilizações com redes sociais nacionais e internacionais que amplificam o poder das populações locais vulneráveis em situações de conflito.

Já o cenário 3 (mais democracia, menos gestão) é o caso em que as decisões são tomadas de forma coletiva através de processos decisórios mais democráticos e inclusivos, ou ainda por políticas sociais mais redistributivas. Porém, dentre os valores perseguidos não se hierarquiza a preocupação com as formas de utilização dos serviços ecossistêmicos. Por isso, embora a riqueza social seja distribuída equitativamente, ainda há vulnerabilidade socioambiental por causa da inadequação da racionalidade instrumental em relação ao manejo dos recursos naturais e energéticos. A diversidade cultural e a afirmação de identidades étnicas encontram aqui um relativo espaço nas esferas social e institucional, com boas perspectivas para desenvolver sua dimensão espiritual, mas com dificuldades para que sua geração de renda garanta um alto padrão de desenvolvimento humano e de melhor sustentabilidade ambiental, inclusive pela restrição econômica que limita implementar tecnologias mais sustentáveis que exigem maiores investimentos. Tal cenário parece próximo da realidade de alguns territórios de certos países latinoamericanos cujos governos possuem maior compromisso histórico com demandas populares. Contudo, permanece difícil reverter a intensa exploração dos ecossistemas e recursos naturais associada à expansão das fronteiras de investimento capitalista na região em sua inserção no comércio internacional, caso da produção energética e de commodities agrícolas e metálicas, assentados em setores e lobbies do agronegócio, da mineração, siderúrgicos e petroquímicos considerados pelos governos como estratégicos para a balança comercial e a ampliação de políticas públicas. Ainda que as políticas sociais e as práticas de gestão ambiental possam delimitar áreas de proteção ambiental e aumentar os direitos de agricultores familiares e de povos tradicionais (originários/indígenas; quilombolas; extrativistas e pescadores artesanais), a natureza mais solidária e frequentemente mais sustentável dos processos de trabalho destes territórios se confronta e é constrangida frente aos padrões de produção e consumo direcionados por lógicas de mercado e valores de qualidade de vida mais urbanos e consumistas. Tais valores se diferenciam e se confrontam com o chamado "bem viver", conceito que vem sendo usado pelos coletivos contra hegemônicos e que considera a liberdade das diferentes formas de desenvolvimento econômico, cultural e espiritual subordinada ao respeito pela natureza e sua proteção.

Finalmente, o cenário 4 (mais democracia, mais gestão) é o melhor cenário possível considerando a permanência do mercado e do fluxo internacional do comércio, porém com padrões diferenciados aos atuais em função de critérios globais mais claros de proteção ambiental e respeito às soberanias locais e regionais. Neste cenário teórico a sociedade, de forma ampla nos 
vários países e continentes, tem consolidada sua democracia e se apropria politicamente dos instrumentos que permitem gerir os recursos naturais e os ecossistemas de forma justa e sustentável. O poder decisório está nas mãos da cidadania, que exerce com soberania e solidariedade o usufruto da riqueza socialmente produzida, com a sociedade e o Estado atuando na defesa dos bens e interesses públicos e impondo restrições ao poder do mercado, permitindo a gestação de outras formas de economia e saberes. Há uma gestão mais democrática e precaucionaria do risco e da produção de conhecimento técnico-científico, o direito à informação está plenamente garantido, gerando as condições de autonomia que renovam a cada momento histórico as relações equivalenciais entre indivíduos, comunidades e coletivos sociais. Desta forma, a diversidade cultural encontra seu espaço na esfera social com múltiplas possibilidades de desenvolvimento humano, tanto nas dimensões materiais quanto espirituais. Este cenário idealmente ótimo não possui, ainda, nenhum exemplo concreto na realidade atual, pois mesmo nas sociedades mais ricas e democráticas da atualidade, tal cenário é restringido pela atual lógica do comércio internacional baseada numa divisão do trabalho e dos riscos que subordina a riqueza de uns à exploração social e à degradação ambiental de outros ${ }^{14,20}$.

Para fins de breve ilustração para compreender a atual realidade brasileira, verificamos uma clara tendência de expansão de práticas compatíveis com o cenário 2 , ao mesmo tempo em que formas violentas de gestão desreguladas e sem a atuação do Estado ainda permanecem, como assassinatos e práticas mafiosas na defesa de interesses econômicos, o que pode ocorrer tanto nos confins da Amazônia como nas periferias de metrópoles como o Rio de Janeiro. Isto é dialeticamente acompanhado por movimentos de institucionalização de práticas cidadãs que aproximam certos contextos do cenário 3 e possibilitam vislumbrar cenários mais otimistas. A presença de grandes investimentos em quase todo o país relacionados à expansão do agronegócio; dos portos de exportação de commodities; das grandes hidrelétricas, hidrovias e ferrovias; dos complexos siderúrgicos e petroquímicos; dos rearranjos urbanos provenientes de grandes eventos como a Copa do Mundo e as Olimpíadas, são todos processos reveladores da inserção brasileira na atual lógica do capitalismo global. Ao mesmo tempo, intensificam conflitos e situações de injustiça ambiental, gerando inúmeras mobilizações coletivas que colocam em seu centro ques- tões de direitos e democracia, conectadas ao ambientalismo e à própria saúde coletiva.

Existem vários processos que, nas próximas décadas, poderão impactar diferentemente os níveis de democracia e gestão ambiental, mesclando, expandindo ou restringindo tendências entre os cenários apontados. Por exemplo, as atuais crises do capitalismo (financeira, social e ambiental), ao mesmo tempo em que geram instabilidades e retrocessos, podem permitir rearranjos de poder dentro dos países e entre eles, através de um maior controle das instituições financeiras e do mercado, bem como de uma multipolaridade que reforce padrões mais democráticos de governança global. Por sua vez, o uso contra hegemônico da internet tem possibilitado enormes avanços para o controle cidadão e a soberania informativa, mas se confronta com as ameaças do espetáculo midiático que aumenta o poder de controle de informações e subjetividades por parte das grandes corporações e mídias a elas associadas.

O aumento dos impactos, ou da percepção dos mesmos, relativos às mudanças climáticas reforça a agenda ambiental nas políticas públicas e práticas de modelos mais eficientes de gestão em diferentes níveis, ressignificada como economia verde ou economia de baixo carbono, associada à criação de novos mecanismos de mercantilização da natureza, como o mercado de carbono e o chamado REDD (Redução de Emissões por Desmatamento e Degradação). Estes temas, vitrine da Conferência Rio+20, devem ser vistos com extrema cautela, pois representam um novo fetiche para a solução de problemas socioambientais que deverão se intensificar nas próximas décadas. Por outro lado, mesmo iniciativas em torno de tecnologias "limpas" renováveis também podem vulnerabilizar populações, caso da implantação de parques eólicos no nordeste brasileiro que acabam afetando ecossistemas, populações tradicionais, pescadores e agricultores familiares.

Outro fator decisivo para o futuro da democracia está relacionado a como a humanidade e os vários países lidarão com ameaças de grande perigo, sejam catástrofes ambientais ligados a grandes interesses corporativos (caso do setor nuclear e a tragédia de Fukushima), ou mesmo atos terroristas de maior envergadura, os quais possam impactar o fluxo de informações, a mobilidade e o exercício de direitos humanos fundamentais. Também o fim ou a localização em poucos países de recursos naturais estratégicos, sejam eles energéticos (petróleo e urânio) ou vitais (água) nas próximas décadas poderão gerar 
práticas mais rigorosas de gestão ambiental, mas também disputas que, em situações de tensão, poderão desembocar em conflitos mais generalizados de natureza bélica. Estes processos serão decisivos para a evolução dos níveis de democracia e gestão do ambiente nas próximas décadas, e por isso representam elementos norteadores da agenda e da ação política por parte dos grupos que pleiteiam mais sustentabilidade ambiental, democracia e justiça.

\section{Breves conclusões}

A dialética produção-destruição, central no capitalismo contemporâneo e concretizada na crise socioambiental ${ }^{2}$, estabelecerá cada vez mais uma dialética entre prudência e os processos de emancipação social, combinando estratégias de reversão dos problemas ambientais em contextos eventualmente dramáticos como desastres e catástrofes ambientais, com a luta pela democratização das sociedades centrada no enfrentamento das assimetrias de poder frente às grandes corporações e suas influência nas instituições, na defesa dos direitos fundamentais e na conquista de processos deliberativos mais próximos dos territórios e das pessoas que nele vivem e trabalham.

Apesar das críticas e limites dos cenários analisados, experiências, movimentos e processos sociais inovadores e democráticos poderão redefinir o significado da ação humana de gerir o ambiente. Sob este ponto de vista, entende-se que a gestão ambiental deverá ser cada vez mais apropriada pela cidadania e consolidada como uma ferramenta dos cidadãos para administrar com soberania o usufruto solidário do seu capital social, natural e cultural. Ainda, o cenário mais favorável a um modelo de desenvolvimento humano mais justo e ecológico - conjugando oikonomos com oikopóios - deve incluir uma gestão plenamente democrática, plural e precaucionária da informação e do conhecimento.

Para isso, um desafio central envolverá o confronto dialético de ruptura e de reconstrução entre formas hegemônicas e contra-hegemônicas. Mais especificamente, como formas legítimas reguladas pelos Estados (lógica da defesa dos direitos coletivos) e autorregulados pelas empresas (lógica empresarial da Ecoeficiência) poderão conviver - sem estrangular - com outras lógicas da economia solidária e da justiça ambiental, assim como por valores culturais locais e tradicionais e expressos em espaços como os Fóruns Sociais ${ }^{20}$ e o Encontro Diálogos e Convergências entre Redes e Movimentos Sociais ${ }^{21}$, que apontam para inúmeras experiências de resistências e alternativas de novas economias e saberes sendo construídos nos territórios, sejam campos e florestas com agricultores e povos originários, sejam urbanos nas periferias e produções culturais de alta qualidade.

Para tanto, o próprio sentido de conhecimento e ciência deverá passar por rupturas e avanços no que poderíamos chamar de uma epistemologia política. Considerar, construir e articular novas epistemologias ${ }^{11,20}$ é estratégico para se compreender e atuar diante da complexidade dos sistemas socioecológicos e novas formas de gestão sustentáveis e humanizadoras.

\section{Colaboradores}

MFS Porto e GE Schütz participaram igualmente de todas as etapas de elaboração do artigo. 


\section{Referências}

1. Freitas CM. Problemas ambientais, saúde coletiva e ciências sociais. Cien Saude Colet 2003; 8(1):137-150.

2. Porto MFS. Uma Ecologia Política dos Riscos: princípios para a promoção da saúde e da justiça ambiental. Rio de Janeiro: Editora Fiocruz; 2007.

3. Fernandes F. A contestação necessária: retratos intelectuais de inconformistas e revolucionários. São Paulo: Ática; 1995.

4. Buarque SC. Metodologia e técnicas de construção de cenários globais e regionais. Brasília: IPEA; 2003. [texto para discussão ${ }^{\circ}$ 939]

5. M'Gonigle RM. Ecological economics and political ecology: towards a necessary synthesis. Ecol Econ 1999; 28:11-26.

6. Funtowicz S, Ravetz J. Emerging complex systems. Futures 1994; 26(6):568-582.

7. Foladori G. Limites do desenvolvimento sustentável. Campinas: Editora Unicamp; 2001.

8. Schütz GE. La insoportable levedad del papel: Conflicto socioambiental y salud en torno de la producción de celulosa en el Cono Sur latinoamericano [tese]. Rio de Janeiro: Fundação Oswaldo Cruz; 2008.

9. Arendt H. A Condição Humana. Rio de Janeiro: Forense Universitária; 2003.

10. Bauman Z. Vida de Consumo. Buenos Aires: Fondo de Cultura Econômica; 2007.

11. Nunes JA. Governação, conhecimentos e participação pública. Coimbra: Centro de Estudos Sociais; 2007.

12. Hagendijk R, Egil K. Changing Conceptions and Practices of Governance in Science and Technology in Europe: A Framework for Analysis. STAGE Discussion paper no. 2. [acessado 2012 maio 14]. Disponível em: http://www.stage-research.net/ STAGE/downloads/StageDiscussPaper2.pdf

13. O'Connor J. Causas Naturales: Ensayos de Marxismo Ecológico. México: Siglo XXI; 2001.
14. Porto MF, Martinez-Alier J. Ecologia política, economia ecológica e saúde coletiva: interfaces para a sustentabilidade do desenvolvimento e para a promoção da saúde. Cad Saude Publica 2007; 23(Supl. 4):S503-S512.

15. Almeida F. O Bom Negócio da Sustentabilidade. Rio de Janeiro: Nova Fronteira; 2002.

16. Freudenburg W, Gramling R, Davidson D. Scientiûc Certainty Argumentation Methods (SCAMs): Science and the Politics of Doubt. Sociological Inquiry 2008; 78(1):2-38.

17. World Commission on the Ethics of Scientific Knowledge and Technology (COMEST). The Precautionary Principle. Paris: UNESCO; 2005.

18. Laclau E. La razón populista. Buenos Aires: Fondo de Cultura Economica; 2008.

19. Kleba J. Adesão voluntária e comportamento ambiental de empresas transnacionais do setor químico no Brasil. Ambiente e Sociedade 2003; 6(2):25-45.

20. Santos BS. A crítica da razão indolente: contra o desperdício da experiência. São Paulo: Cortez Editora; 2000.

21. Tygel D. Carta Política do Encontro Nacional de Diálogos e Convergências entre Agroecologia, Saúde e Justiça Ambiental, Soberania Alimentar, Economia Solidária e Feminismo. 2004. [acessado 2012 maio 14]. Disponível em: http://dialogoseconvergencias.org/noticias/ carta-politica-do-encontro-nacional-de-dialogos-econvergencias.

Apresentado em 27/04/2012

Versão final apresentada em 02/05/2012 